\title{
Cytotoxicity Tests for Nanostructured Chitosan/PEO Membranes Using the Agar Diffusion Method
}

\author{
Valcinir Aloisio Scalla Vulcani*, Maria Trindade Marques Bizarria ${ }^{\mathrm{b}}$, Marcos Akira d'Ávilac, \\ Lucia Helena Innocentini Mei ${ }^{\mathrm{b}}$, Cláudia Bernal ${ }^{\mathrm{d}}$,Janice Rodrigues Perussi ${ }^{\mathrm{d}}$ \\ ${ }^{a}$ Animal Anatomy, Federal University of Goiás - UFG, Rua Riachuelo, CP 03, \\ CEP 75804-020, Jataí, GO, Brazil \\ ${ }^{\mathrm{b}}$ School of Chemical Engineering, State University of Campinas - UNICAMP, \\ Cidade Universitária Zeferino Vaz, Av. Albert Einstein, 500, CEP 13083-852, Campinas, SP, Brazil \\ ${ }^{\circ}$ Department of Materials Engineering, School of Mechanical Engineering, \\ State University of Campinas - UNICAMP, CP 6122, CEP 13083-970, Campinas, SP, Brazil \\ ${ }^{\mathrm{d} C h e m i s t r y ~ I n s t i t u t e ~ o f ~ S a ̃ o ~ C a r l o s, ~ U n i v e r s i t y ~ o f ~ S a ̃ o ~ P a u l o ~-~ U S P, ~}$ \\ Av. Trabalhador São-carlense, 400, CP 780, CEP 13560-970, São Carlos, SP, Brazil
}

Received: May 9, 2011; Revised: January 24, 2012

\begin{abstract}
Electrospinning is used to produce fibers in the nanometer range by stretching a polymeric jet using electric fields of high magnitude. Chitosan is an abundant natural polymer that can be used to obtain biocompatible nanostructured membranes. The objectives of this work were to obtain nanostructured membranes based on blends of chitosan and polyoxyethylene (PEO), and evaluate their thermal and morphological properties, as well as their in vitro biocompatibility by agar diffusion cytotoxicity tests for three different cell lines. A nanostructured fibrous membrane with fiber diameters in the order of $200 \mathrm{~nm}$ was obtained, which presented a rough surface and thickness ranging from one to two millimeters. The results of the cytotoxicity tests evidenced that the chitosan/PEO membranes are non-toxic to the cells studied in this work. Further, the electrospinning technique was effective in obtaining nanostructured chitosan/PEO membranes, which showed biocompatibility according to in vitro preliminary tests using the cell lines.
\end{abstract}

Keywords: nanotechnology, biomaterials, biocompatibility, electrospinning

\section{Introduction}

Polymeric nanofibers can be produced using many different techniques, such as phase separation, self-assembly and electrospinning ${ }^{1}$. Electrospinning is the only technique that allows dimensional control, fiber formation in different arrangements, use of several polymers and production in great quantities compared to the other methods ${ }^{2}$. This technique is based on the application of high magnitude electric potentials $(5-50 \mathrm{kV})$ and low current $(0.5-1 \mu \mathrm{A})$ in which a jet of fluid material is accelerated and stretched, producing fibers of reduced diameter ${ }^{3-5}$.

Chitosan is derived from chitin deacetylation and is a natural polymer that is suited for electrospinning in order to produce nanostructured fibrous mats. Usually, the electrospinning of chitosan requires blending this polymer with other biocompatible synthetic polymers such as PEO. Chitosan has been used for many years in tissue regeneration ${ }^{6}$, in some drug delivery controlled systems ${ }^{7}$, for covering wounds and for other biomedical devices. Several studies have shown the chitosan biocompatibility in different forms (membranes, gel, composites, films and matrices). Therefore, there is an increasing interest in the production of chitosan-based nanostructured biomaterials ${ }^{8-11}$.

*e-mail: aloisiosv@ hotmail.com
A biomaterial should be biocompatible and present an appropriate response for a specific situation, causing minimum allergic, inflammatory and toxic reactions when in contact with live tissues or organic fluids ${ }^{12}$. The normative instruction number 10993 from the International Standard Organization describes that in vitro assays are normally done as screening tests in the first phase of the biocompatibility evaluation. The in vitro evaluation can supply fast and financially accessible results about biological interactions and decrease the use of animals in research ${ }^{13}$. Cytotoxicity tests are done in vitro and evaluate the toxic effect for the cells of some materials, which can be cell death, changes in membrane permeability, enzymatic inhibition, etc. This technique uses cell culture and the toxicity can be measured quantitatively by cell lysis (cell death), inhibition of cell growth and other effects caused by the devices, materials and extracts. The cells used to make cultures are acquired from previously established lines and supplied by resellers of biological products or cell and tissue banks, such as the American Tissue Culture Collection (ATCC) due to the high reproducibility, efficiency and availability ${ }^{14-15}$. 
The objective of this study was to obtain nanostructured membranes of Chitosan/Peo using the electrospinning technique. The membrane characterization was performed by its thermal and morphological characteristics and the evaluation of their biocompatibility was achieved by using the agar diffusion method to assess the cytotoxicity of the membranes in three cell lines.

\section{Materials and Methods}

\subsection{Membrane preparation}

The membranes were prepared by chitosan of medium molecular weight with deacetylation degree of $80 \%$ and viscosity of 284 cps obtained from Aldrich ${ }^{\circledR}$, glacial acetic acid PA from Synth ${ }^{\circledR}$ and poly ethylene oxide (PEO), 900,000 g.mol ${ }^{-1}$, also from Aldrich ${ }^{\circledR}$. All materials were used as received and the deionized water was used to compose the solvent system.

The electrospinning equipment used to obtain chitosan/PEO membranes was built at the "Escola de Engenharia Química do Departamento de Tecnologia de Polímeros da Universidade de Campinas* (UNICAMP), Campinas, SP, Brazil" with the following components: high voltage power supply, a $10 \mathrm{ml}$ glass syringe (Luer lock inlet) containing a stainless steel needle with internal diameter of $1 \mathrm{~mm}$, an electrode, a sustaining claw for the syringe (connected to a sustaining support for the claw), a grounded-aluminum-collector and a rotary-device ( $\approx 80 \mathrm{rpm})$ constituted by a $3.2 \mathrm{~cm}$ diameter stainless steel tube between the capillary and the collect table ${ }^{16-19}$.

Membranes were made by the electrospinning technique according to the methodology described by Bizarria et al. (2009) ${ }^{19}$ using the setup described in the previous paragraph and the blend composed by three parts of a $4 \%\left(\mathrm{w}_{\mathrm{w}} \mathrm{w}^{-1}\right)$ chitosan solution and one part of a $3 \%\left(\mathrm{w} \cdot \mathrm{v}^{-1}\right)$ PEO solution, resulting in a final concentration of approximately $80 \%$ chitosan and $20 \%$ PEO. This blend composition was selected to make the membranes because, among the solution blends that showed good processing conditions, in the referred previous study, it was the one with greatest chitosan concentration.

Preparing the $4 \%\left(\mathrm{w}_{\mathrm{W}} \mathrm{w}^{-1}\right)$ chitosan solution, an aqueous solution with high concentration of acetic acid $90 \%\left(\mathrm{v}^{-1} \mathrm{v}^{-1}\right)$ was used as solvent. The chitosan solution was left under magnetic stirring (not being removed) until its complete homogenization, which took a few days. The $3 \%\left(\mathrm{w}^{-\mathrm{v}^{-1}}\right)$ PEO solution was prepared under magnetic stirring using deionized water as solvent. To prepare the blend solution to be electrospun, a part of the 3\% PEO solution (by volume) was added to 3 parts (by weight) of the $4 \%$ chitosan solution. The resulting blend was left under magnetic stirring for two hours before being electrospun. The preparation of the solutions, as well as the preparation of the blend solution and its electrospinning process were run at room temperature. The flow rate was determined by the viscosity of the solution being approx. $1 \mathrm{~mL} / \mathrm{h}$. and the distance between the needle tip to collector cylinder $7.5 \mathrm{~cm}$ at an applied voltage of $20 \mathrm{kV}$.

\subsection{Membrane characterization}

Scanning electron microscopy (SEM) was carried out on a JEOL model JXA-840 A apparatus at an accelerating

\footnotetext{
* School of Chemical Engineering of the Polymer Technology Department of the State University of Campinas.
}

voltage of $25 \mathrm{kV}$. All samples were sputtered with gold prior an high magnitude electric potentials alysis.

Differential scanning calorimetry (DSC) was performed under $\mathrm{N}_{2}$ flow rate of $50 \mathrm{~mL} / \mathrm{min}$, in a DSC 2920 apparatus from TA Instruments, under a heating rate of $10^{\circ} \mathrm{C} / \mathrm{min}$, in the temperature range between -100 and $250{ }^{\circ} \mathrm{C}$.

\subsection{Cell culture}

The assays were performed at the "Instituto de Química de São Carlos da Universidade de São Paulo**** (USP), São Carlos, SP, Brazil" using the cell lines HEp-2 (human larynx carcinoma), VERO (African green monkey kidney cells) and McCoy (mouse fibroblasts) at the concentration of $3.0 \times 10^{5}$ cells. $\mathrm{mL}^{-1}$. The cells were grown in Petri $(60 \times 15 \mathrm{~mm})$ dishes with a volume of $5 \mathrm{~mL}$ of ISCOVE's medium by 24 hours. After this period, the culture medium was removed and discarded, and $5 \mathrm{~mL}$ of a $(1: 1)$ mixture composed by ISCOVE's medium and agar $1.8 \%$ containing $0.01 \%$ of neutral red were added ${ }^{15}$.

\subsection{Cytotoxicity evaluation using the agar diffusion method}

Fragments of the membrane measuring about $0.25 \mathrm{~cm}^{2}$ of superficial area were placed on agar before their complete solidification. The Petri dishes were kept in the cell incubator with $5 \% \mathrm{CO}_{2}$ at $37{ }^{\circ} \mathrm{C}$ during 24 hours.

Latex fragments were used as positive control and confirmedly non-toxic filter paper discs as negative control, respecting the dimension of the superficial area. The plates were analyzed macroscopically and microscopically using the halo presence and the cell integrity around the sample as parameters, respectively ${ }^{15}$.

\section{Results}

\subsection{Macroscopic and microscopic characteristics of chitosan/PEO membranes}

Visual and manual inspections evidenced that the membranes obtained had rough aspect and were very thin, with about one to two millimeters thickness. Figure 1 shows the photograph of the membrane fragment.

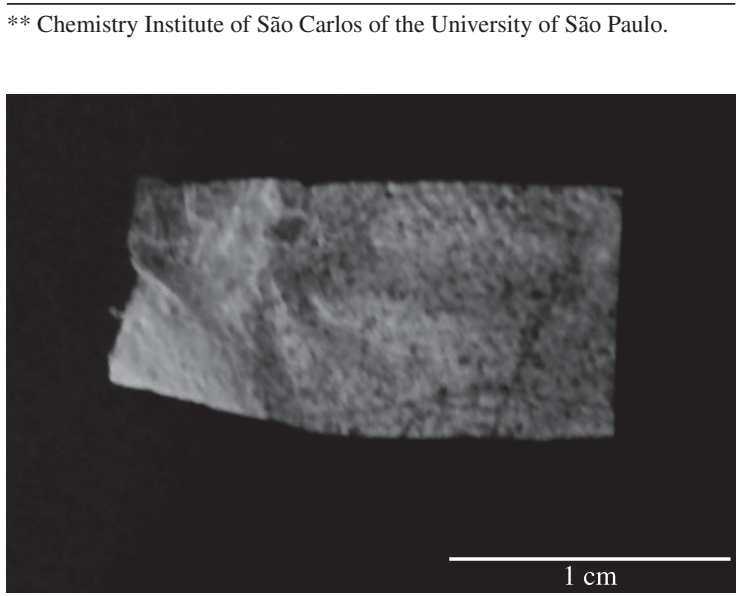

Figure 1. Fragment of the chitosan membrane obtained by electrospinning. Notice the rough surface and the low thickness. 


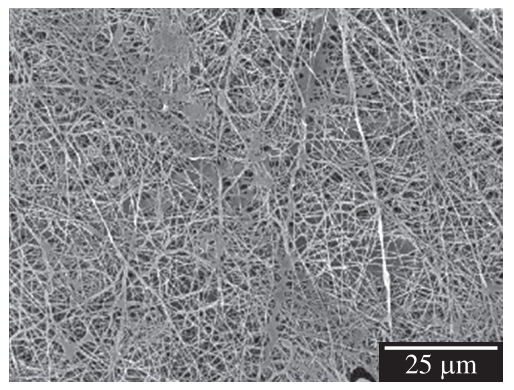

(a)

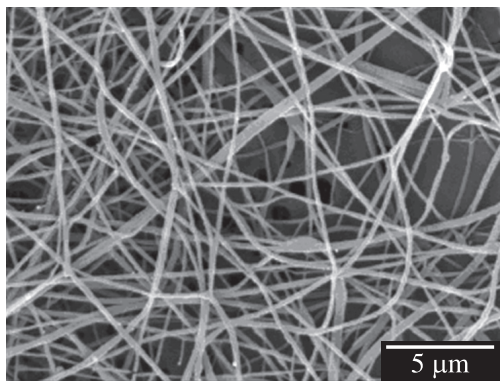

(b)

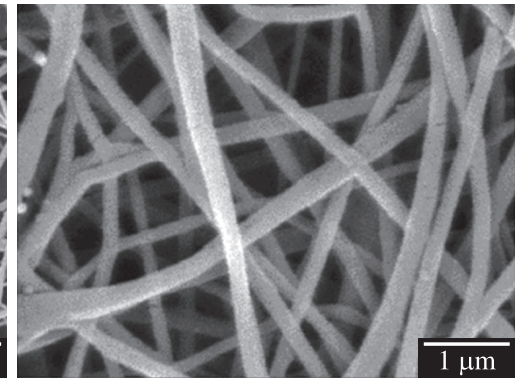

(c)

Figure 2. SEM images of $80 \%$ chitosan/20\% PEO membranes, a) $300 \times$ magnification; b) $5,000 \times$ magnification; and c) $20,000 \times$ magnification.

Figure 2 shows, in different magnitudes, SEM images of an $80 \%$ chitosan $/ 20 \%$ PEO membrane obtained by electrospinning process in which it is possible to observe a non-woven structure composed of fibers whose diameters range between the submicron and nanoscale.

\subsection{Thermal properties}

The DSC curves are presented in Figure 3. The pure chitosan DSC curve shows only a single thermal event corresponding to the dehydration of chitosan, while the DSC curve of pure PEO also shows only one endothermic event with its peak at approx. $70{ }^{\circ} \mathrm{C}$, which refers to the crystalline melt of the pure PEO. Finally, the thermogram of the blend of chitosan/PEO presents two endothermic events, which show their maximum intensities at the temperatures of PEO melting and dehydration of chitosan. Hence it can be concluded that the blend preparation and the electrospinning process did not affect significantly the thermal properties of their two original components.

\subsection{In vitro biocompatibility evaluation}

The toxicity using the agar diffusion method is evidenced by the presence of a halo around the material tested. This halo is observed when cell lysis occurs, releasing the neutral red staining incorporated by cells and giving a transparent appearance to the area ${ }^{15}$.

The results of the cytotoxicity tests with the membrane prepared with cell lines showed that the three cell lines did not present halo formation around the fragments of chitosan nanostructured membrane similarly to the negative controls, suggesting that the material is not cytotoxic to fibroblasts and epithelial cells (Figures 4, 5 and 6). The use of three lines originated from human, monkey and mouse cells reinforce the large applicability of the membrane prepared since it demonstrated to be biocompatible in all cases.

This non-toxic characteristic of the chitosan was observed by Amaral et al. (2006) ${ }^{20}$, who submitted blends of collagen and chitosan to the same in vitro cytotoxicity tests, i.e., the agar diffusion method. Despite the fact that the chitosan membrane used by that author was not nanostructured, their result corroborates with the present material biocompatibility findings. Similarly, Asia et al. $(2006)^{21}$ verified the in vitro biocompatibility of chitosan films by submitting them to human fibroblast cultures and

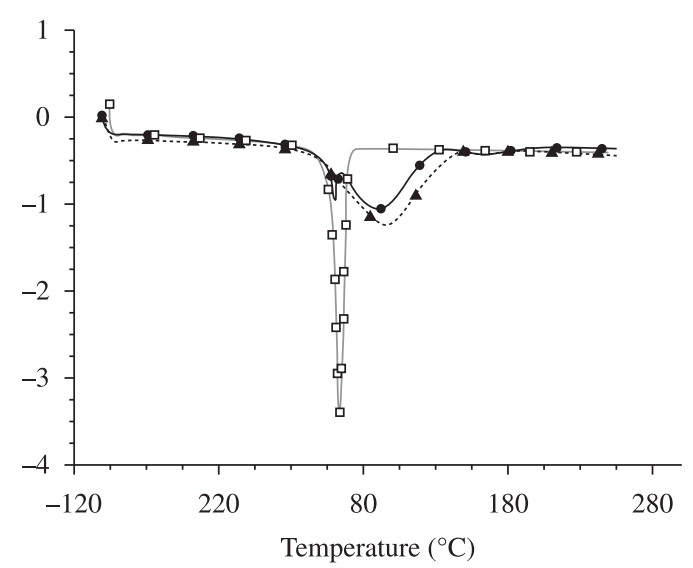

$\rightarrow$ Blend Chitosan/PEO $\rightarrow$ PEO $\rightarrow$ - Chitosan

Figure 3. DSC of pure chitosan, pure PEO and of the $80 \%$ chitosan/20\% PEO blend membrane.

concluded that their substance was non-toxic and could be used as a biomaterial. Oliveira et al. (2008) $)^{22}$ submitted chitosan samples in diverse concentrations to in vitro cytotoxicity tests and confirmed that changes in chitosan concentrations did not affect the non-toxic characteristic of the material, however, $\mathrm{pH}$ variations of the formulations caused cell lysis. Brito et al. (2009) ${ }^{23}$ implanted chitosan membranes in the subcutaneous of rats for biocompatibility evaluation and observed a little inflammatory reaction with fibrosis formation (pseudocapsule) around the samples. The authors stated that the characteristics observed allow to consider that the material can be used for tissue repair. In another study ${ }^{24}$, nanostructured chitosan composites were used as a growth matrix for human fibroblasts. The authors verified that the presence of nanostructured chitosan favored the cell proliferation, imitating the extracellular matrix properly. These results are similar to those found by Brito et al. ${ }^{23}$ using collagen and chitosan nanostructured membranes as a growth matrix for human fibroblasts verifying the non-toxic characteristic for cells. The authors of that study also used the composites in animals to verify the effectiveness on skin healing, and concluded that the composite showed better results when compared to commercially available collagen membranes. 


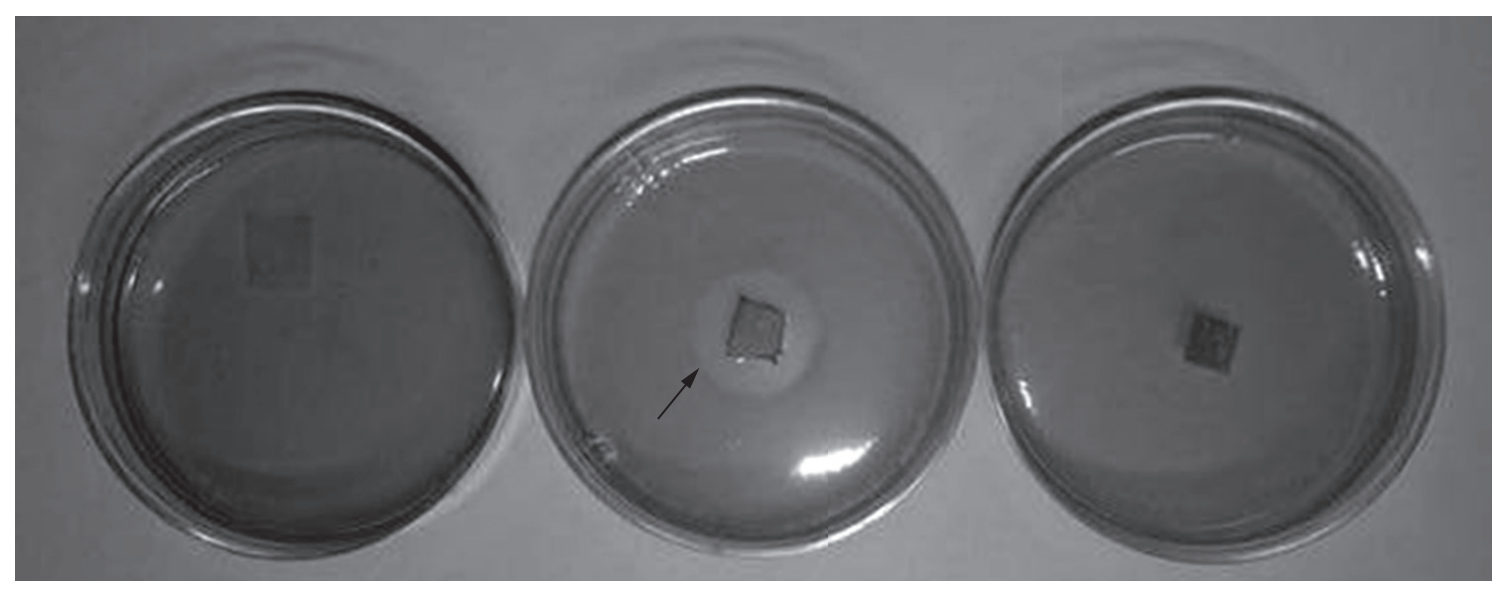

(a)

(b)

(c)

Figure 4. Digital photograph of the Petri dishes containing the cell line HEp-2 (human larynx carcinoma) and the sample of the nanostructured chitosan membrane (a), positive control using latex (b) and negative control using filter paper (c). The halo formation was observed just around the positive control (arrow) demonstrating that the chitosan nanostructured samples are not cytotoxic.

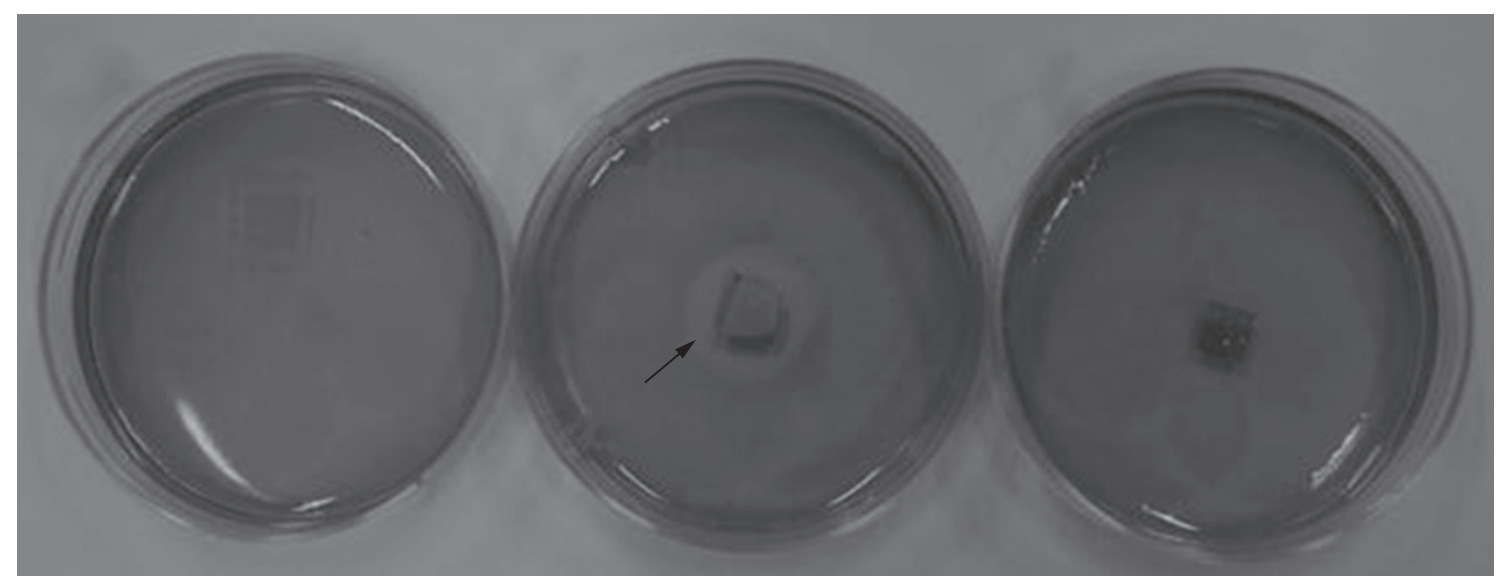

(a)

(b)

(c)

Figure 5. Digital photograph of the Petri dishes containing the cell line Vero (African green monkey kidney cells) and the sample of nanostructured chitosan membrane (a), positive control using latex (b) and negative control using filter paper (c). The halo formation was observed just around the positive control (arrow) demonstrating that the chitosan nanostructured samples are not cytotoxic.

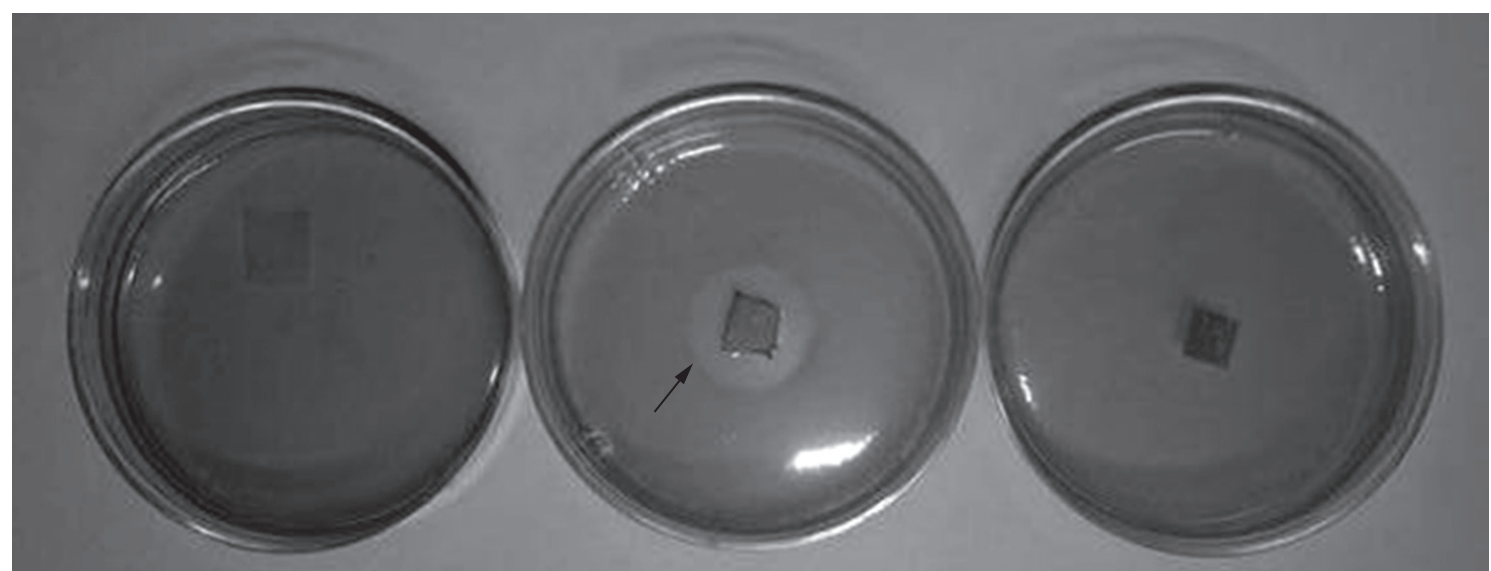

(a)

Figure 6. Digital photograph of the Petri dishes containing the cell line McCoy (mouse fibroblasts) and the sample of the nanostructured chitosan membrane (a), positive control using latex (b) and negative control using filter paper (c). The halo formation was observed just around the positive control (arrow) demonstrating that the chitosan nanostructured samples are not cytotoxic. 
In this way, the results presented in this paper agree with results reported previously with chitosan membrane that suggest that the material is biocompatible.

\section{Conclusion}

Chitosan/PEO biocompatible fibrous mats were successfully obtained by electrospinning. A non-woven structure with fiber diameter on the nanometer range was observed by SEM. Results from DSC have shown that the electrospinning process did not affect significantly the original thermal properties of both chitosan and PEO. The agar diffusion method applied for three different cell lines, that is, HEp-2 (human larynx carcinoma cells), Vero (African green monkey kidney cells) and McCoy (mouse fibroblasts cells) proved the biocompatibility of the chitosan electrospun membrane, which makes it suitable for further in vivo tests.

\section{References}

1. Zeng J, Chen X and Liang Q. Ultrafine fibers electrospun from biodegradable polymers. Journal of Applied Polymer Science. 2003; 4:1085-1092. http://dx.doi.org/10.1002/ app. 12260

2. Yarin AL, Koombhongse $\mathrm{S}$ and Reneker DH. Bending instability in electrospinning of nanofibers. Journal of Applied Physics. 2001; 89(5):3018-3026. http://dx.doi. org/10.1063/1.1333035

3. Li D and Xia Y. Electrospinning of Nanofibers: Reinventing the Wheel?. Advanced Materials. 2004; 16(14):1151-1170. http:// dx.doi.org/10.1002/adma.200400719

4. Lannutti J, Reneker D, Tomasko D and Farson D. Electrospinning for tissue engineering scaffolds. Materials Science and Engineering. 2007; 27:504-509. http://dx.doi. org/10.1016/j.msec.2006.05.019

5. Pham Q. Electrospinning of Polymeric Nanofibers for Tissue Engineering Applications: A Review. Tissue Engineering. 2006; 12(5):101-110. PMid:16771634. http:// dx.doi.org/10.1089/ten.2006.12.1197

6. Laranjeira MCM and Favere VT. Quitosana: biopolímero funcional com potencial industrial biomédico. Química Nova. 2006; 32(3):672-678. http://dx.doi.org/10.1590/S010040422009000300011

7. Hamman JH. Chitosan based polyelectrolyte complexes as potential carrier materials in drug delivery systems. Marine Drugs. 2010; 8(4):1305-1322. http://dx.doi.org/10.3390/ md8041305

8. Nair R, Haritha Reddy B, Ashok Kumar CK and Jayraj Kumar K. Application of Chitosan microspheres as drug carriers : A Review. Journal of Pharmaceutical Sciences and Research. 2009; 1(2):1-12.

9. Costa Silva HSR, Dos Santos KSCR and Ferreira EI. Quitosana: derivados hidrossolúveis, aplicações farmacêuticas e avanços. Química Nova. 2006; 29(4):776-785. http://dx.doi. org/10.1590/S0100-40422006000400026

10. Sinha VR, Singla AK, Wadhawan S, Kaushik R and Kumria R. Chitosan microspheres as a potential carrier for drugs. International Journal of Pharmaceutics. 2004; 274:1-33. http:// dx.doi.org/10.1016/j.ijpharm.2003.12.026

11. Berger J, Reist M, Mayer JM, Felt O and Gurny R. Structure and interactions in chitosan hydrogels formed by complexation or aggregation for biomedical applications. European Journal of Pharmaceutics and Biopharmaceutics. 2004; 57:35-52. http://dx.doi.org/10.1016/S0939-6411(03)00160-7

12. Hench LL, Pereira MM, Oréfice RL and Jones JR. Biocompatibilidade, bioatividade e engenharia de tecidos. In: Oréfice RL, Pereira MM and Mansur HS. Biomateriais: Fundamentos e Aplicações. Rio de Janeiro: Cultura Médica; 2006. cap. 16, p. 479-506.
13. International Organization for Standardization - ISO. ISO 10993-5: Biological evaluation of medical devices, Part 5 , Tests for cytotoxicity: in vitro methods. ISO; 1992.

14. International Organization for Standardization - ISO. ISO 10993-1: Biological evaluation of medical devices, Part 1, Guidance on selection of test. ISO; 1992.

15. Rogero SO, Lugao AB, Ikeda TI and Cruz AS. Teste in vitro de citotoxicidade: estudo comparativo entre duas metodologias. Material Research. 2003; 6(3):27-39. http:// dx.doi.org/10.1590/S1516-14392003000300003

16. Ramakrishna S, Fujihara K, Lim T-C and Ma Z. An introduction to electrospinnig and nanofibers. Singapore: World Scientific Publishing Co. Ltd.; 2005.210 p. http://dx.doi. org/10.1142/9789812567611

17. Jacobs V, Patanaik A and Anandjiwala RD. The influence of electrospinning parameters on the structural morphology and diameter of electrospun nanofibers. European Cells and Materials. 2010; 9(1):4-10.

18. Costa LMM, Bretas RES and Gregorio FIlho R. Caracterização de filmes de PVDF- $\beta$ obtidos por diferentes técnicas. Polímeros. 2009; 19(3):183-189. http://dx.doi.org/10.1590/ S0104-14282009000300005

19. Bizarria MTM, Davila MA, Feijó LA, Marques MCS and Mei LH. Innocentini. In: Anais do 10th Congresso Brasileiro de Polímeros; 2010. CBPol; 2010. v. 1, p. 1-6.

20. Amaral MB. Citotoxicidade in vitro e biocompatibilidade in vivo de compósitos a base de hidroxiapatita, colágeno e quitosana. [Dissertação]. São Carlos: Universidade de São Paulo; 2006.

21. Asiah MN, Halim AS, Lau HY, Ujang Z and Hazri A. Biocompatibility of chitosan films in fibroblastos culture. The Malaysian Journal of Medical Science. 2006; 13(1):207-219.

22. Oliveira AP, Motisuke M, Beppu MM, Zavaglia CAC, Higa O and Rodas A. Cimentos de fosfato de cálcio contendo solução de quitosana a diferentes pHs. In: Anais do 21th Congresso Brasileiro de Engenharia Biomédica, 2008, Salvador. Salvador; 2008. p. 255-258.

23. Brito MKM, Schellini SA, Padovani CR, Pellizon $\mathrm{CH}$ and Trindade Neto CG. Inclusões de quitosana no subcutâneo de rato: avaliação clínica, histológica e morfométrica. Anais Brasileiros de Dermatologia. 2009; 84(1):35-40. http://dx.doi. org/10.1590/S0365-05962009000100005

24. Duan B, Wu 1, Li X, Yuan X, Li X, Zhang Y, Yao K. Degradation of electrospun plga-chitosan/pva membranes and their cytocompatibility in vitro. Journal of Biomaterials Science. 2009; 18(1):95-115. http://dx.doi. org/10.1163/156856207779146105 